\title{
Localized surface activity of torso, a receptor tyrosine kinase, specifies terminal body pattern in Drosophila
}

\author{
Jordi Casanova and Gary Struhl \\ Howard Hughes Medical Institute, Center for Neurobiology and Behavior, Columbia University College of Physicians and \\ Surgeons, New York, New York 10032 USA
}

\begin{abstract}
The subdivision of the Drosophila body into distinct terminal and central domains depends on the torso (tor) protein, a putative receptor tyrosine kinase that is active at both ends of the early embryo. We show that the tor protein is uniformly expressed along the surface membrane of early embryos despite its localized activity at both poles. Further, we present evidence that polarized activity of this protein depends on other terminal gene functions, one of which may be a localized extracellular ligand generated during oogenesis. Finally, using the temperature-sensitive gain-of-function mutation tor $^{R L 3}$, we show that different levels of active tor protein can specify distinct portions of the terminal pattern. Thus, we argue (1) that tor functions as a ubiquitous surface receptor that is activated by a spatially restricted ligand, and $(2)$ that localized activity of the tor kinase may generate one or more gradients of intracellular signals that control body pattern.
\end{abstract}

[Key Words: Drosophila; torso protein; terminal gene functions]

Received September 13, 1989; revised version accepted October 16, 1989.

Genetic analysis in Drosophila has identified many genes involved in specifying the body pattern (e.g., Lewis 1978; Nüsslein-Volhard and Wieschaus 1980; Schüpbach and Wieschaus 1986a; Nüsslein-Volhard et al. 1987). This process begins during oogenesis when a few localized determinants are laid down under the control of a small number of genes (Nüsslein-Volhard et al. 1987). After fertilization, these determinants organize the body pattern by directing the expression of subordinate regulatory molecules, the products of the gap, pairrule, segment-polarity, and homeotic genes (for review, see Ingham 1988).

Distinct anterior and posterior determinant systems act in concert to control where most of the head, thoracic, and abdominal segments arise (Nüsslein-Volhard et al. 1987). Both depend on single morphogens (bicoid and nanos, respectively) that are initially localized at opposite ends of the embryo and then diffuse or are transported towards the middle forming opposing concentration gradients (Frohnhöfer and Nüsslein-Volhard 1986, 1987; Lehmann and Nüsslein-Volhard 1986, 1987; Driever and Nüsslein-Volhard 1988a,b; Nüsslein-Volhard et al. 1987; Lehmann 1988). The terminal portions of the body are specified by a third determinant system (Nüsslein-Volhard et al. 1987). As in the case of the anterior and posterior systems, this system appears to depend on the localized activity of a single gene function, torso (tor) (Klingler et al. 1988).

The tor gene is only one of several terminal genes for which loss-of-function mutations cause the enlargement of the central body segments at the expense of the terminalia (Perrimon et al. 1985, 1986; Degelmann et al. 1986; Schüpbach and Wieschaus, 1986a; Nüsslein-Volhard et al. 1987). It is unique, however, because gain-offunction mutations that cause the opposite phenotype - the expansion of the terminalia at the expense of the trunk segments - have also been isolated (Klingler et al. 1988; Strecker et al. 1989). In the most extreme cases, the enlarged head and tail meet in the middle of the embryo, and the trunk segments are eliminated (the splice phenotype; Schüpbach and Wieschaus 1989). Thus, presence or absence of tor activity can be viewed as defining alternative states of a developmental switch-'on' specifying terminal development; 'off' leading to central development by default. It follows that the normal subdivision of the embryo into distinct end and middle parts depends on tor being active at both poles but inactive or absent from the middle (Klingler et al. 1988).

The terminal system differs significantly from the anterior and posterior systems because it does not appear to be associated with a localized transplantable factor (Klingler et al. 1988). Instead, cytoplasm obtained from any position along the body appears to be able to restore the development of terminal structures when microinjected into tor mutant embryos. Hence, at present, the conclusion that tor activity is normally restricted to the poles rests solely on the genetic properties of the tor gene, particularly the reciprocal phenotypes caused by its gain- and loss-of-function mutations.

Recently, Sprenger et al. (1989) discovered that the tor 
gene encodes a putative transmembrane protein that is structurally similar to a number of receptor tyrosine kinases. Moreover, these authors have found that the tor mRNA is ubiquitously distributed in maturing oocytes and early embryos. These findings suggest that tor protein may normally be expressed at the cell surface of the embryo and raise several questions about how the protein comes to be active only at the poles and about how it governs the specification of the end parts of the body.

Here we describe a series of experiments directed toward determining where the tor protein is expressed and how its distribution relates to its localized activity and the development of the terminalia. Our results establish that the tor protein is expressed in tight association with the surface membrane of early embryos and is ubiquitously distributed along the cell surface. Moreover, our data provide evidence suggesting that the protein exists in active and inactive forms and that transition to the active form requires an interaction with a localized factor present at both poles. Finally, we show that different levels of active tor protein are capable of dictating the development of different portions of the terminalia. Thus, our results support the proposal that the tor protein functions as a ubiquitous surface receptor that responds to a localized extracellular ligand and suggest that activated tor protein, or possibly its phosphorylated substrates, may organize body pattern by acting as gradient morphogens.

\section{Results}

Isolation of the tor gene and generation of antiserum directed against the tor protein

The subdivision of the early embryo into distinct domains of central and terminal pattern depends on localized tor activity (Klingler et al. 1988; Strecker et al. 1989; see Introductory section). Given the recent discovery that tor protein is likely to be a transmembrane receptor (Sprenger et al. 1989), it is reasonable to suppose that the protein is expressed at the surface of the early, syncytial embryo and that its activation involves an interaction with an extracellular ligand. Accordingly, either of two mechanisms could suffice for localized tor activity: (1) tor protein concentrated at both ends of the embryo may be activated by a ubiquitously distributed ligand or (2) tor protein expressed ubiquitously along the surface may be activated by ligand deposited only in the vicinity of the poles. To examine these possibilities, we cloned the gene, generated an antiserum against its encoded protein, and then used this antiserum to determine the distribution of tor protein in early embryos.

The tor gene was cloned by standard techniques using a revertable P-element-induced mutation (tor ${ }^{T C-17}$ ) generously provided by T. Schüpbach (see Methods). The gene is entirely contained within an EcoRI fragment of about $11.5 \mathrm{~kb}$ that fully rescues the tor mutant phenotype when reintroduced into the genome. cDNAs homologous to the tor transcript were obtained. One of these encodes a polypeptide that begins at amino acid 68 in the tor protein, ends at around amino acid 600, and contains most of the putative extracellular domain, the transmembrane domain, and the first $\sim 180$ amino acids of the intracellular kinase domain (see Sprenger et al. 1989|. This tor polypeptide was synthesized in bacteria and used to raise rat polyclonal antiserum (see Methods). The antiserum specifically detects tor protein, as indicated by the following three criteria: (1) wild-type embryos show consistent immunohistochemical staining in contrast to embryos derived from $\operatorname{tor}^{T C-17} /$ tor $^{T C-17} \mathrm{fe}$ males, which do not (e.g., Fig. $1 \mathrm{~A}-\mathrm{C}$ ); (2) embryos derived from females with extra copies of the tor $^{+}$gene (see below) show correspondingly higher levels of immunohistochemical staining (e.g., Fig. 1E); and (3) some mutations that abolish tor function (e.g., tor ${ }^{P M}$ ) show normal patterns of immunohistochemical staining (see Methods). This last piece of evidence eliminates the possibility that the antiserum recognizes a protein induced by tor rather than the tor protein.

\section{Uniform expression of tor protein on the surface of early embryos}

Wild-type embryos, or embryos derived from females carrying eight copies of the tor gene (see below), were assayed for tor protein expression using a variety of immunohistochemical detection systems (see Methods). These experiments provide information about the onset of tor protein expression, its distribution along the anteroposterior body axis, and its subcellular distribution, which we describe in turn.

We can first detect tor protein expression in wild-type embryos around the ninth nuclear division after fertilization, at which stage the nuclei have just arrived at the egg periphery. The level of protein then increases during the next several nuclear division cycles prior to cellularization of the blastoderm stage and the onset of gastrulation. Thereafter, it diminishes gradually over a period of 1-2 hr, after which we can no longer detect it. We also examined the time course of appearance in embryos derived from females carrying eight wild-type copies of the tor gene. Increasing the gene dosage allowed us to detect tor protein expression as early as the fourth or fifth nuclear cycle, suggesting that it is normally expressed in wild-type embryos at this stage. However, we still failed to detect tor protein expression in earlier embryos or in freshly laid eggs. Because tor mRNAs are known to be transcribed during oogenesis and to persist in the early embryo (Sprenger et al. 1989), our results suggest that the mRNA is not translated until after fertilization.

Throughout the period when we can detect tor protein expression, the protein appears to be associated with the cell surface (Fig. 1A-C; see below). Moreover, we find no evidence of localized expression of tor protein at the ends of the body, despite the genetic evidence indicating that tor activity is concentrated in these regions of the body. Indeed, in whole mount preparations (e.g., Fig. 1A), the staining intensity appears to be somewhat diminished at the poles and along the ventral side. This apparent decrease in signal intensity can be attributed at 

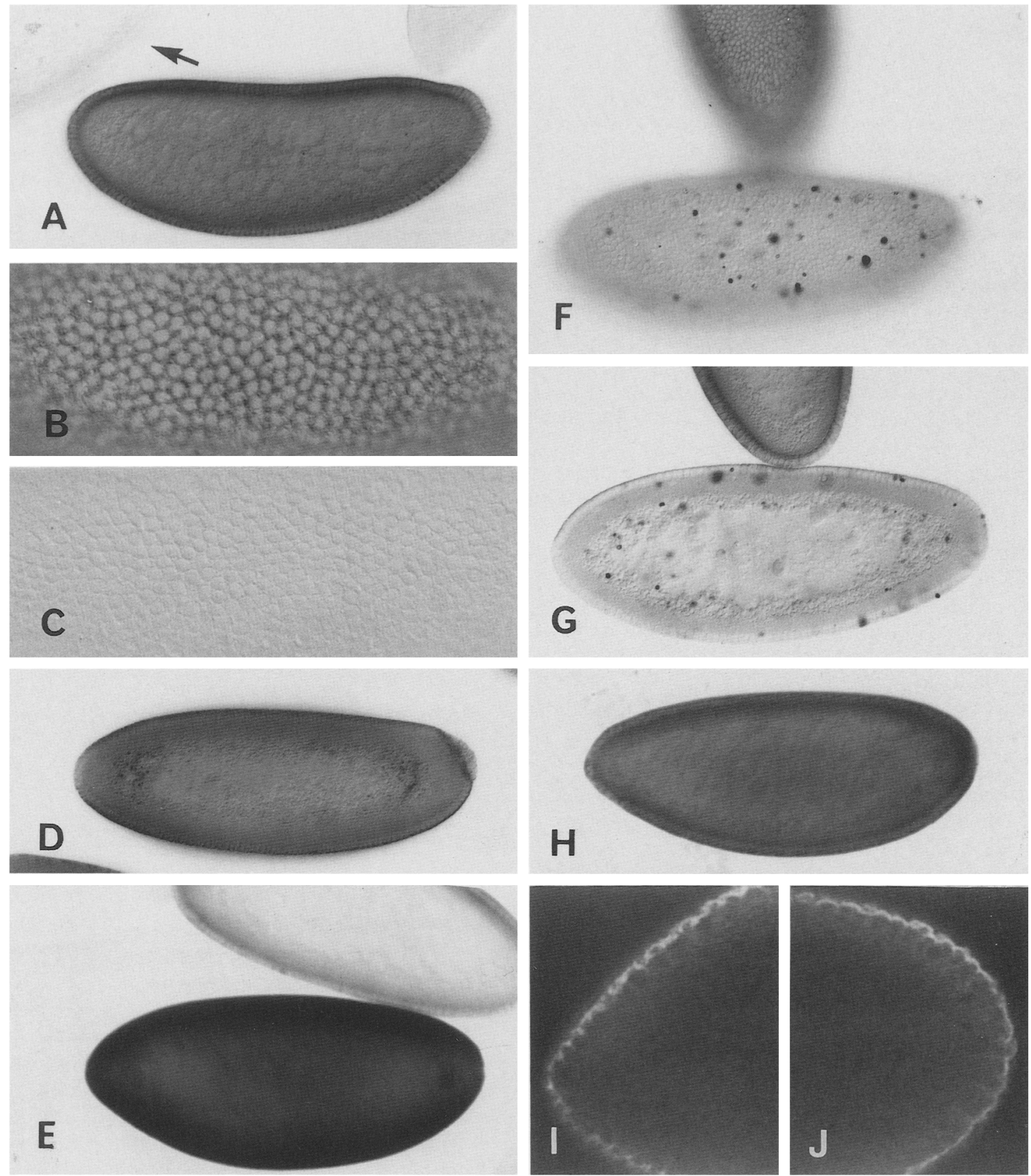

Figure 1. tor protein expression in wild-type and mutant embryos. $(A, B$, and $C)$ The pattern of tor protein expression in tor ${ }^{+}$and tor ${ }^{T C-17}$ mutant embryos as revealed by immunohistochemistry (see Methods). tor $^{+}$and tor $^{T C-17}$ embryos were fixed and stained together (the tor ${ }^{+}$embryos were mutant for the bcd and osk gene functions and hence, could be readily distinguished from tor ${ }^{T C-17}$ embryos because they lacked pole cells; see Methods). An optical cross section of a tor ${ }^{+}$embryo at the beginning of nuclear cycle 14 is shown in $A$. tor protein expression can be seen to be more concentrated at the cell periphery. Moreover, the protein is not localized at the poles, despite genetic evidence indicating that it acts selectively in the terminal regions. (Upper left) Arrow indicates a tor ${ }^{T C-17}$ embryo at the same stage; no staining is detectable. The surfaces of both these embryos are shown at higher magnification in $B$ and $C$. Note that tor protein appears to be expressed in a lattice pattern; in double labeling experiments in which the nuclei are labeled independently, the lattice network outlines the positions of the nuclei. As shown in Fig. 2, the lattice pattern of expression reflects the higher density of membrane folded into grooves separating the nuclei. $(D)$ An optical section of a mutant trk embryo stained for tor protein expression; the pattern of staining is similar to that of $t o r^{+}$embryos $(A)$. $(E)$ Optical sections of a pair of embryos, the lower derived from a female carrying eight copies of the $t o r^{+}$gene, the upper from a wild-type (two-copy) female; this micrograph is underexposed to give a better indication of the relative difference in tor staining intensity between the two embryos. ( $F$ and $G$ ) Different focal planes of a pair of embryos, one wild type $(t o p)$ and the other derived from a female carrying two copies of the gain-of-function mutation tor ${ }^{R L 3}$. Both embryos developed at $25^{\circ} \mathrm{C}$. Note that the level of tor protein expressed at the cell surface is reduced in the mutant relative to wild-type embryo; however, large abnormal intracellular vesicles appear throughout the mutant embryo, some of which express high levels of tor protein. These vesicles are readily observed in the peripheral egg cytoplasm, even in unstained preparations, as this region is usually free of yolk granules and other cytoplasmic inclusions. $(H)$ Expression of tor protein in embryos derived from females heterozygous for a dominant gain-of-function mutation, tor ${ }^{D 4021}$, which is similar to wild type $(A)$ and $\operatorname{trk}(D)$. ( $I$ and $I)$ Images of tor staining at the anterior and posterior poles, respectively, obtained with the confocal scanning microscope (see also Fig. 2). Note that staining is continuous along the surface, although the level of staining appears higher dorsally (upper halves of each micrograph). 
least in part to an optical artifact that results from the changing shape of the egg cell and the superimposition of signal in and out of the plane of focus; as it is less apparent when tor protein expression is monitored by confocal scanning microscopy (Fig. 1I,J).

When viewed in optical cross section by conventional microscopy (Fig. 1A), most of the tor protein appears to be associated with the cell surface, although the signal cannot be precisely localized because of the presence of signal in other focal planes. When the surface is viewed directly (Fig. 1B), tor protein staining exhibits a latticelike pattern outlining the regularly spaced nuclei that lie just beneath the cell surface. To gain a more highly resolved image, we examined the distribution of tor protein using a confocal scanning microscope (Fig. 2). Under these conditions, we find that tor protein is ubiquitously distributed over the cell surface, the lattice pattern observed by conventional microscopy resulting from infoldings of the surface membrane that form around the perimeters of adjacent nuclei present just beneath the surface (Fig. 2; see also Turner and Mahowald 1976; Warn and Magrath 1982; Foe and Alberts 1983). We find no evidence for staining in the underlying nuclei or cytoplasm. Similar results are also obtained when embryos stained for tor protein by histochemical means are examined in 2-4- $\mu \mathrm{m}$ plastic sections (data not shown).

Thus, tor protein is tightly associated with the external cell membrane of the early syncytial embryo; moreover, we find no evidence for localized expression of the protein at either end of the embryo. These results rule out the possibility that localized tor activity revealed by genetic experiments reflects a local distribution of the protein. Hence, one must posit that the protein is selectively activated at both poles, or alternatively that it is active everywhere, but that the substrates on which it acts are tightly restricted.

\section{tor protein expression in gain-of-function mutant embryos}

The existence of gain-of-function tor mutations that cause central portions of the body to develop into terminalia argues strongly for local activation of the tor protein, rather than a polarized distribution of its substrates (Klingler et al. 1988). Otherwise, it is difficult to see how such splice phenotypes could arise, since critical intermediates in the terminal signaling system would be absent in the middle of the embryo. Indeed, additional genetic experiments [Klingler et al. 1988, unpubl. [as cited in Sprenger et al. 1989)] confirm that these intermediate factors must be present in the middle of the embryo for gain-of-function mutations to cause the splice phenotype. For tor protein to be locally activated, it must be able to exist in active and inert states depending on the presence of other factors. Accordingly, gain-of-function tor mutations that cause ectopic activity in the middle of the embryo may relax the normal dependence of the protein on these factors, allowing it to function constitutively. Such gain-of-function mutations would not be expected to cause a change in the distribution or level of tor protein.
One gain-of-function mutation, tor ${ }^{D 4021}$, is a simple dominant allele; embryos derived from heterozygous females develop as if the tor protein is active indiscriminately throughout the body (Klingler et al. 1988). We cannot detect any differences betv. een tor protein expression in embryos derived from wild-type or tor ${ }^{D 4021 /}$ + females (Fig. 1H).

A second gain-of-function mutation, $\operatorname{tor}^{R L 3}$ (Schübpach and Wieschaus 1989), has unusual genetic properties (Klingler et al. 1988; Strecker et al. 1989). Females carrying two copies of the tor $^{R L 3}$ mutant allele give rise to splice embryos with greatly expanded terminal domains and few if any intervening body segments, even if they also carry a wild-type allele. This phenotype is temperature sensitive: mutant embryos develop almost normally at $17^{\circ} \mathrm{C}$ but show an extreme splice phenotype at $25-29^{\circ} \mathrm{C}$. Females carrying only a single tor $^{R L 3}$ allele, whether alone or in the presence of a wild-type allele, generally give rise to normal larvae, although at $25-29^{\circ} \mathrm{C}$, these larvae often show weak splice phenotypes such as the partial deletion of segments in the middle of the abdomen (Klingler et al. 1988; Strecker et al. 1989; data not shown). Hence, the level of ectopic tor activity caused by this mutation seems to depend critically on both temperature and the concentration of mutant protein (as determined by the number of copies of the mutant genel.

We find that embryos derived from $t^{R L 3} / \operatorname{tor}^{R L 3} \mathrm{fe}-$ males at $25^{\circ} \mathrm{C}$ or $29^{\circ} \mathrm{C}$ (and hence having high levels of ectopic tor activity) generally express lower levels of tor protein at the cell surface (Fig. 1F,G). Both the yolk and peripheral cytoplasm, however, contain large vesicles, some of which show intense expression of the tor protein (Fig. 1F,G). These vesicles are not found in normal embryos and can also be observed in the peripheral cytoplasm of unstained mutant embryos using Nomarski optics. The number of abnormal vesicles, as well as the reduction in surface expression, is variable. We have not observed these vesicles in embryos derived from tor ${ }^{R L 3 /}$ + or $t_{0 r^{R L 3} /}$ - females, and they appear less frequently in embryos derived from tor $^{R L 3} /$ tor $^{R L 3}$ females at lower $\left(17-22^{\circ} \mathrm{C}\right)$ temperatures. Thus, as in the case of tor $^{4021}$, the $\operatorname{tor}^{R L 3}$ mutation appears to cause centrally located protein to become active rather than remain inert. However, this mutation has the unusual property that conditions that cause high levels of indiscriminate $\operatorname{tor}^{R L 3}$ activity (i.e., high temperature and high concentration of mutant protein) also appear to be associated with a shift of the mutant protein from the cell surface toward membrane compartments within the cell.

\section{Mutations in other terminal genes block localized activation of the tor protein}

Several genes aside from tor, notably trunk (trk), torsolike (tsl), female sterile (1) pole hole [fs(1)ph] and female sterile (1) Nasrat [ $\left.f_{s}(1) N\right]$, are required during oogenesis for the development of terminal pattern at both ends of the developing embryo (Degelmann et al. 1986; Perrimon et al. 1986; Schüpbach and Wieschaus 1986a; 

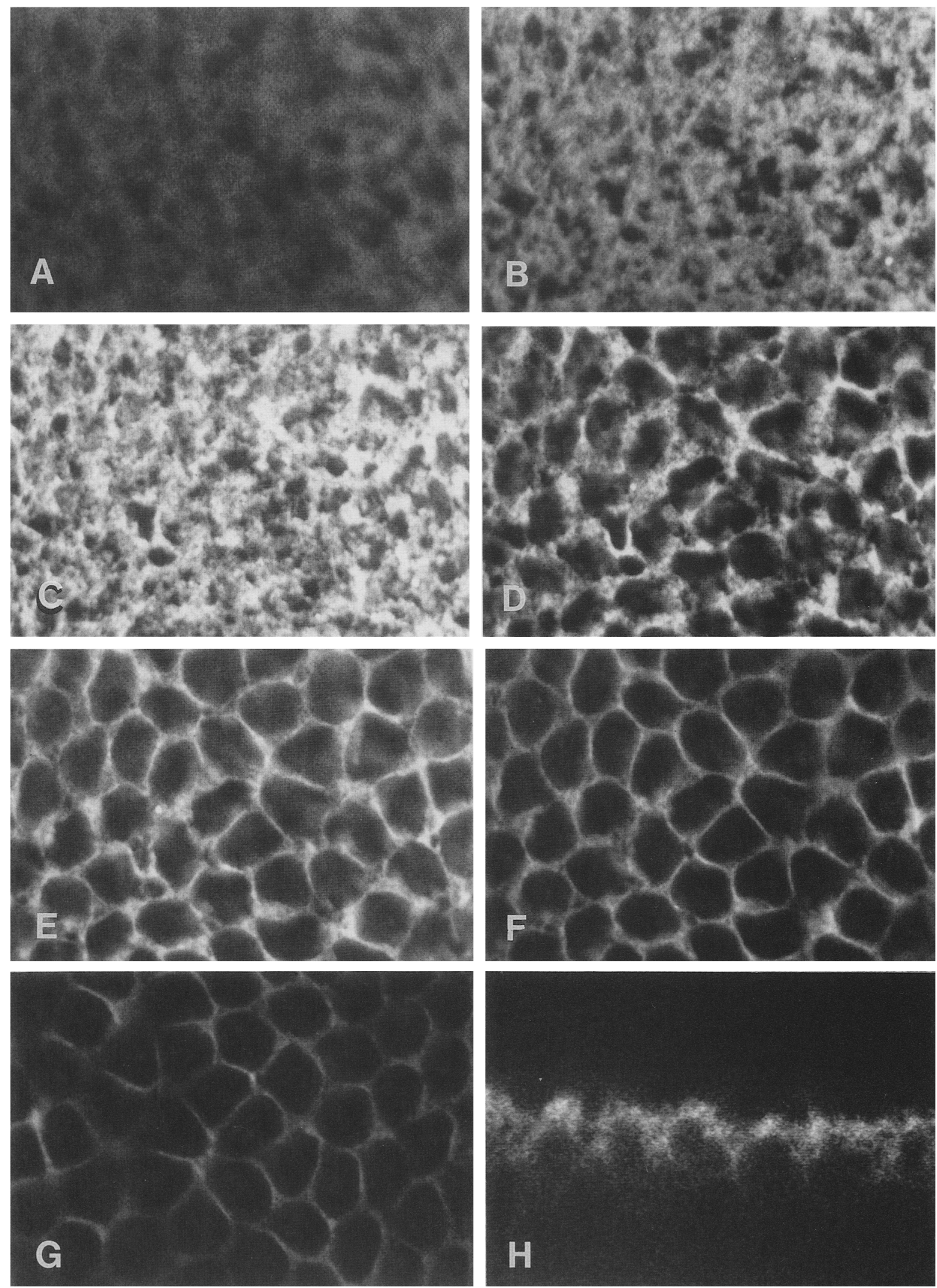

Figure 2. tor protein expression at the cell surface of the early embryo. The expression of tor protein early in nuclear cycle 14 is shown in a series of optical sections obtained using a confocal scanning microscope. The first plane of focus $(A)$ is just above the surface of the embryo; $(B-G)$ A progression of focal planes obtained at $1-\mu \mathrm{m}$ intervals; $(H)$ Optical section of the edge of the embryo. tor protein can be seen to be tightly associated with the surface of the embryo $(B$ and $C \mid$, as well as with infoldings of the membrane that partially separate adjacent nuclei $(D-G)$. Significant expression is not observed in the nuclei or in the underlying cytoplasm $(H)$. The embryo shown was derived from a female carrying eight wild-type copies of the tor gene; similar results were obtained with embryos from females with two copies, although the level of staining was much lower, reducing the resolution of the image. 
Nüsslein-Volhard et al. 1987). That is, embryos derived from mutant females behave as if they lack tor activity. These other gene functions could be required for early expression of tor protein on the cell surface. Alternatively, they may be involved in activating tor protein, or in mediating the response of downstream functions to its activity. Mutations that block tor protein expression should be readily distinguishable from the other classes of mutations by antibody staining. We examined the distribution of tor protein in embryos derived from females that lack or have reduced function of the $t r k, t s l$, $f_{s}(1) p h$, and $f_{s}(1) N$ genes (see Methods for exact genotypes). In all cases (e.g., Fig. 1D), we find that tor protein expression in mutant embryos is indistinguishable from that of wild-type embryos.

Thus, the products of these other terminal genes appear to be required either for the local activation of tor protein, or for mediating the response to activated tor protein. These two possibilities are distinguishable because constitutive forms of the tor protein should restore terminal signaling in embryos in which the normal activation step is blocked; however, embryos unable to respond to active tor protein will remain so irrespective of mutations causing constitutive gain of tor activity.

In the case of the trk and $t s l$ genes, we find that the loss-of-function phenotype can be overridden by the gain-of-function mutation $\operatorname{tor}^{R L 3}$. Specifically, embryos derived from doubly mutant trk tor ${ }^{R L 3} /$ trk tor $^{R L 3}$ and tor $^{R L 3 /} /$ tor $^{R L 3}$; tsl/tsl females at $25^{\circ} \mathrm{C}$ show the typical splice phenotype normally exhibited by embryos derived from singly mutant tor $^{R L 3} /$ tor $^{R L 3}$ females at the same temperature (see Methods for exact genotypes). As may be expected, embryos derived from $t r k / t r k$ or $t s l / t s l$ females that carry a single tor $^{R L 3}$ allele show a partial suppression of the terminal phenotype, depending on temperature (see Figs. 4 and 5 and below). We also find that a single tor $^{R L 3}$ allele similarly suppresses the terminal phenotypes caused by reduced function of the $f_{S}(1) p h$ and $f_{S}(1) N$ genes.

Thus, the trk, tsl, $f_{s}(1) p h$, and $f_{s}(1) N$ gene functions all appear to be required for activation of the tor protein. Mutations in both the $f_{S}(1) p h$ and $f_{S}(1) \mathrm{N}$ genes cause a variety of other pleiotropic phenotypes during oogenesis (Counce and Ede 1957; Perrimon et al. 1986), suggesting that these genes are not specifically involved in the activation of tor protein. However, this is not the case for mutations in the trk or tsl genes, suggesting that their products may play a more direct role.

\section{Superabundance of tor protein does not alter terminal patterning}

The foregoing results indicate that tor protein is initially inert when it is first expressed on the surface of the embryo, but that it is differentially activated at both ends by interactions with other signaling molecules, possibly the products of the trk or tsl genes. To gain a better understanding of how the normal distribution of tor activity is achieved, we examined the consequences of changing the total concentration of tor protein on the apparent distribution of active protein.
Conventional genetic techniques were used to generate flies with up to six copies of the $P\left(\mathrm{ry}^{+}\right.$, tor $\left.^{+}\right)$genes introduced into the genome by P-element-mediated transformation (Methods). Embryos derived from females carrying a total of eight copies of the tor gene (two endogenous and six transduced genes) express much higher levels of tor protein, as assayed by immunohistochemistry (Fig. 1E). Nevertheless, such embryos give rise to normal larvae and adults, consistent with the conclusion that superabundance of tor protein has little if any effect on the distribution of active tor protein. However, the embryo can compensate for dramatic alterations of its initial fate map during the development of the larval body pattern (e.g., Berleth et al. 1988; Driever and Nüsslein-Volhard 1988b). Hence, we used two additional assays to test whether superabundance of tor protein causes any changes in the initial fate map. The first assay involved the expression of fushi tarazu ( $f t z$ ). Periodic expression of the pair-rule gene $f t z$ provides an early indication of the pattern of body segments and has proven to be a sensitive measure of changes in the initial fate map, particularly in the case of tor lack-of-function and gain-of-function mutations (Mlodzik et al. 1987; Klingler et al. 1988; Strecker et al. 1989; see also below and Fig. 5). As shown in Figure 3A-C, the patterns of $f t z$ expression in embryos derived from females with one or eight copies of the tor gene are indistinguishable from each other, but clearly distinguishable from that of tor ${ }^{-}$ embryos. The second assay involved Krüppel $|K r|$ expression in bicoid oskar (bcd osk) mutant embryos. The gap gene $K r$ is normally activated during the syncytial blastoderm stage in a precisely defined central domain. In bcd osk mutant embryos, which lack both the anterior and posterior determinant systems, the central domain of $K r$ gene expression is broader than in wild-type embryos (Gaul and Jäckle 1986). Further, under these conditions, the anterior and posterior boundaries of $\mathrm{Kr}$ expression depend primarily if not exclusively on the distribution of active tor protein, as indicated by the fact that triply mutant tor bcd osk embryos express $\mathrm{Kr}$ protein uniformly throughout the embryo (Fig. 3E). Embryos derived from bcd osk females carrying either two or six copies of the tor gene were generated by standard genetic means (see Methods) and then assayed for expression of $\mathrm{Kr}$ protein. All showed indistinguishable patterns of $K r$ expression (e.g., Fig. 3F,G), arguing strongly that the distribution of active tor protein remains unaffected despite the difference in tor protein concentration.

In the experiments described above, we assayed the distribution of tor activity only indirectly, by its influence on the patterns of expression of genes like $f t z$ and $K r$. Because our results were negative-changes in tor gene dosage had no apparent effect on the localized expression of these subordinate genes-it was necessary to test whether these assays are capable of detecting altered distributions of tor activity. Therefore, as a positive control, we asked whether we could detect evidence for an altered distribution of tor activity in embryos derived from females carrying a single copy of the $\operatorname{tor}^{R L 3}$ gain-offunction mutation. 

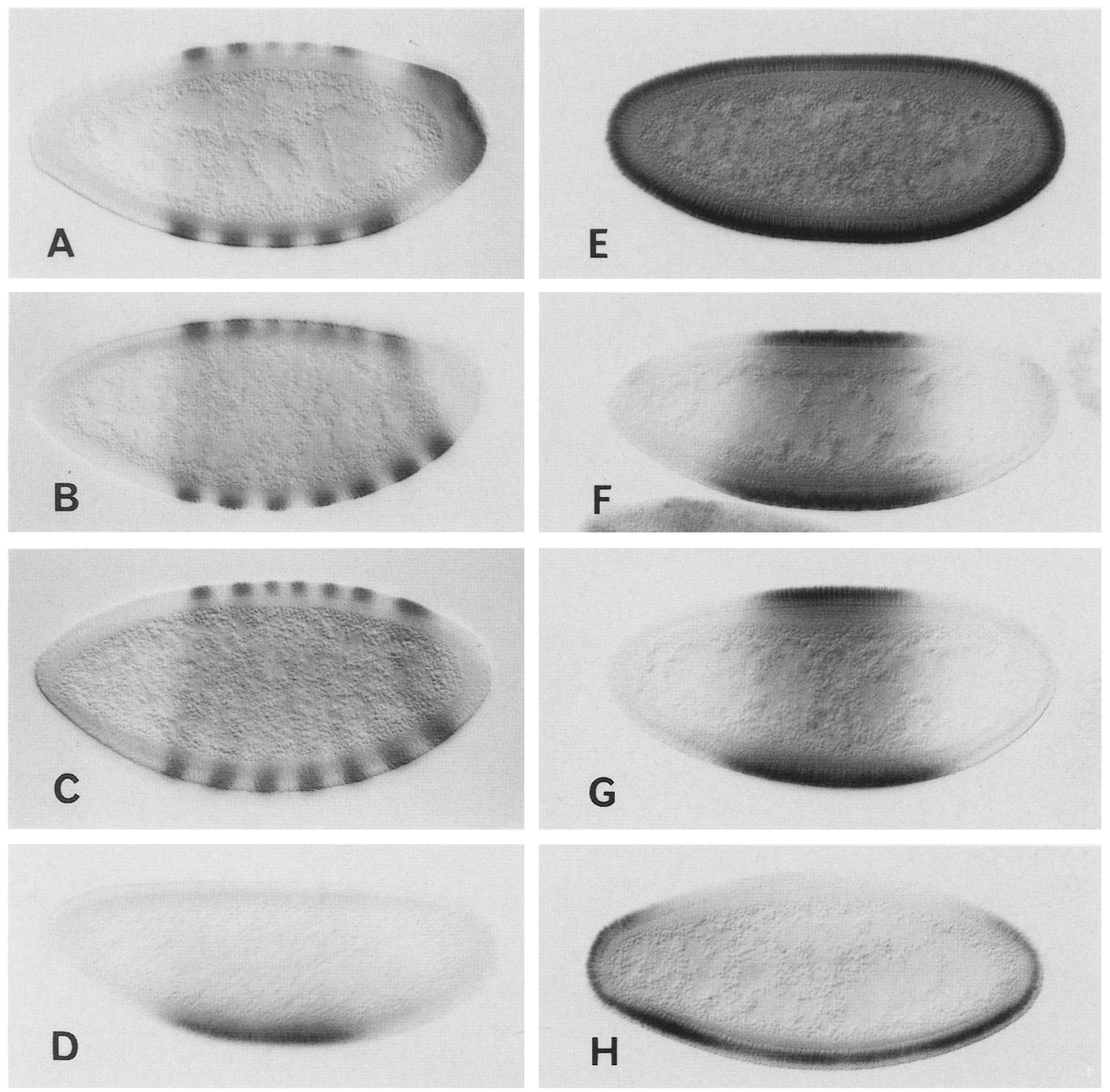

Figure 3. Superabundance of tor protein does not alter body patterning. The expression of the pair-rule gene $f t z$ is shown in embryos derived from females carrying zero, one, and eight functioning copies of the tor gene in $A$, $B$, and $C$, respectively (all embryos are oriented with their anterior ends to the left, dorsal side up). Embryos derived from females with one and eight copies express the normal pattern of seven $f t z$ stripes. In contrast, embryos derived from females with zero copies show an abnormal pattern of expression in which the most posterior (seventh) stripe is absent, and stripe six is broader than normal and shifted to the posterior pole. The expression of the gap gene $K r$ is shown in embryos derived from $b c d$ osk females carrying zero, two, or six functioning copies of the tor gene in $E, F$, and $G$, respectively. Under these conditions (absence of both the anterior and posterior determinant systems), the pattern of $K r$ expression is determined solely by the activity of the terminal signaling system. As shown in $E$, bcd osk embryos lacking tor protein activity express $K r$ uniformly. However, embryos with two and six copies show similar patterns of central $K r$ expression. The expression of $K r$ protein was also examined in bcd osk embryos in which the only active tor protein derives from a single copy of the tor ${ }^{R L 3}$ mutant allele. In embryos derived from $t o r^{R L 3} / t r^{P M}$; bcd osk females at $25^{\circ} \mathrm{C}, K r$ protein is expressed in a broad central domain similar to that observed in bcd osk embryos with two or six copies ( $F$ and $G$ ), or a further abbreviated pattern of expression such as that shown in $D$, or not expressed at all. Hence these embryos behave as if the distribution of active tor protein has two components: the normal distribution found in bcd osk embryos as well as a low level of indiscriminate activity. In some of these embryos, the level of indiscriminate activity is sufficiently high to partially or completely abolish $\mathrm{Kr}$ expression in the central domain of the embryo. In embryos derived from tor ${ }^{R L 3} /+$; bcd osk $t s l$ females at $25^{\circ} \mathrm{C}, K r$ protein is expressed uniformly as in bcd osk tsl (E) and tor; bcd osk embryos, or in abbreviated patterns such as that shown in $H$, or not expressed at all. Hence, these embryos behave as if the tor activity derives solely from constitutive gain of function of the tor ${ }^{R L 3}$ protein, $K r$ expression being partially or completely abolished when this level of activity reaches a critical threshold. The altered pattern of $K r$ expression that results from the presence of a single copy of the tor $^{R L 3}$ mutant allele serves as a positive control for the absence of any detectable effect of raising the gene dosage from two to six copies. Two additional points are noteworthy. First, in bcd osk embryos in which the central domain of $K r$ expression is partially repressed by ectopic tor ${ }^{R L 3}$ function, we invariably observe that it is lost in the dorsal rather than the ventral half. Second, the number of pole cells is usually reduced or absent in embryos derived from females with eight copies suggesting that high levels of tor activity can interfere with determination of the germ line, an event which normally occurs before the major accumulation of tor protein. 
As described previously (Klingler et al. 1988; Strecker et al. 1989) and above, tor ${ }^{R L 3}$ protein behaves as if it is normally activated at the poles, but also as if it is constitutively active throughout the body, the level of constitutive activity being relatively low when the mother carries only a single copy of the mutant gene. As shown
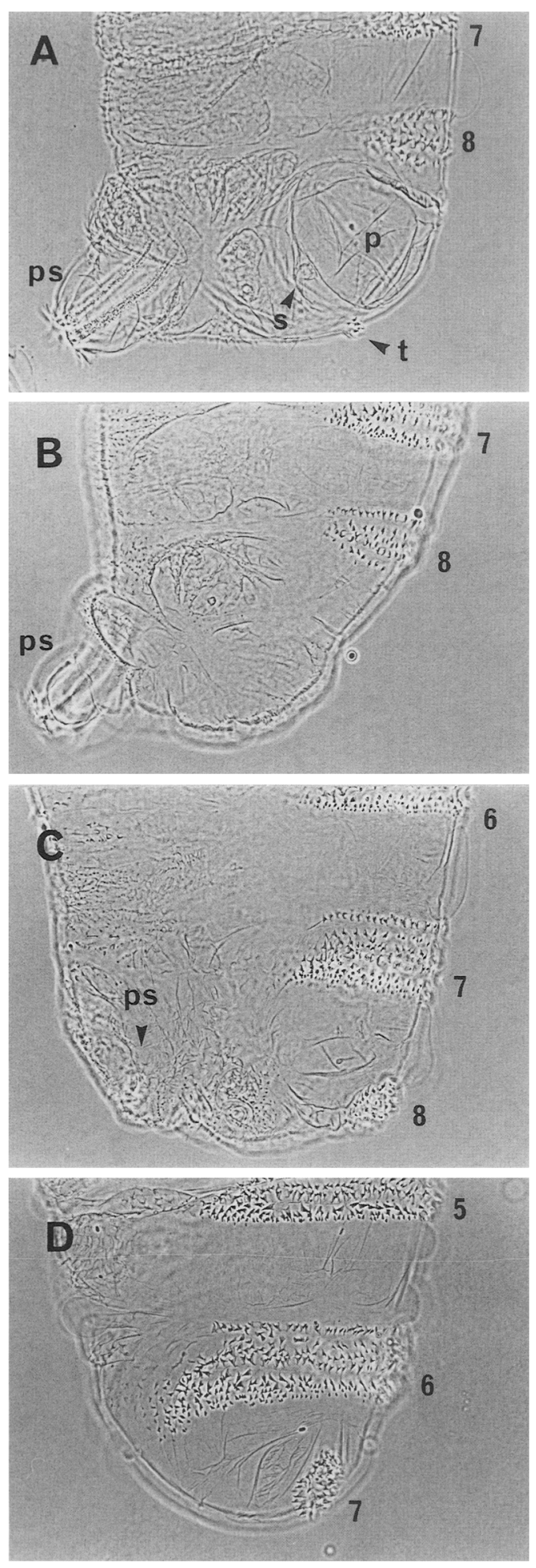

in Figure 3D, the central domain of $K r$ expression is usually abbreviated or eliminated in embryos derived from $b c d$ osk females that are also tor ${ }^{R L 3} /$ - (unlike embryos derived from $b c d$ osk females carrying up to six copies of the tor $^{+}$gene; Fig. 3G). This change in the expression of $K r$ protein can be attributed solely to the constitutive activity of the tor ${ }^{R L 3}$ protein. Embryos derived from $t o r^{R L 3 /}+$; bcd osk tsl females, in which the local activation of both tor $^{+}$and tor $^{R L 3}$ protein is blocked because of a lack of tsl gene function, usually fail to express any $K r$ protein or show only incomplete expression throughout the body (e.g., Fig. $3 \mathrm{H}$ ). As described in the next section (see also Figs. 4 and 5), the periodic pattern of $\mathrm{ftz}$ expression is also altered under similar conditions.

Thus, we can readily detect minor changes in the distribution of tor activity that are attributable to a single copy of the $t o r^{R L 3}$ mutation in the female. Hence, our failure to detect any evidence for such changes when the wild-type gene dosage is varied over an eightfold range indicates that the distribution of active tor protein is not closely coupled to the total concentration of tor protein. This result is most compatible with the notion that activation of the wild-type tor protein normally involves direct contact with a localized factor that is present in limiting quantity. Accordingly, the distribution of this factor would dictate the same distribution of active tor protein, even if the total concentration of tor protein is increased abnormally by changing the gene dosage.

\section{Evidence for distinct responses to different levels of tor protein activity}

As described in the introductory section, the distribution of active tor protein plays a determinative role in distinguishing terminal from central portions of the

Figure 4. Graded responses to incremental changes in the level of activity of tor protein. trk tor ${ }^{R L 3} / t r k$ females give rise to embryos in which the only tor activity is attributable to constitutive gain-of-function of the $t o r^{R L 3}$ mutant protein. Moreover, the level of constitutive $t o r^{R L 3}$ activity is temperature sensitive, increasing as the temperature rises. The cuticular phenotypes of larvae derived from such females at 29,25 , and $17^{\circ} \mathrm{C}$ are shown in $A, B$, and $C_{;}$a larva derived from trk/trk females at $17^{\circ} \mathrm{C}$ is shown in $D$. All micrographs show lateral/ventral aspects of the posterior terminalia. In larvae that develop at $29^{\circ} \mathrm{C}(A)$, virtually all of the posterior terminal structures are present, including the anal tuft $(t)$, anal sense organs $(s)$, anal pads (p) (in more than $60 \%$ of the embryos), posterior spiracles (ps) (in 95\% of the embryos), and all of the denticle bands associated with the posterior abdominal segments (A8 and A7) (in all the embryos). At somewhat lower temperatures $\left(25^{\circ} \mathrm{C} ; B\right)$, the most terminal structures $(t, s$, and $p)$ appear in only $10 \%$ of the embryos, while the less terminal structures (ps, A8 and A7) remain at the back end. At $17^{\circ} \mathrm{C}(C)$, when tor ${ }^{R L 3}$ activity is even further reduced, additional structures (ps and $A 8$ ) are rudimentary or absent (the A8 denticle belt appears in only $30 \%$ of the embryos). Finally, in the absence of any tor function $(D)$, all the terminal structures are absent and the A7 denticle belts appear in only $50 \%$ of the embryos. 
body. However, the nature of this role is uncertain. In particular, it is not clear if the distribution of active protein organizes the pattern of terminal structures, or merely subdivides the embryo into terminal and central patterning domains. One way to distinguish these possibilities is to ask whether different levels of tor activity specify discrete portions of the terminal pattern. If such a relationship exists, it would argue that the distribution of active tor protein normally dictates the pattern of the terminalia. Conversely, the absence of such a relationship would suggest a simpler "switch" role in specifying terminal as opposed to central patterning.

To examine the relationship between the level of tor activity and the development of distinct portions of the terminalia, we made use of the unusual properties of the tor $^{R L 3}$ mutation. As described previously and above

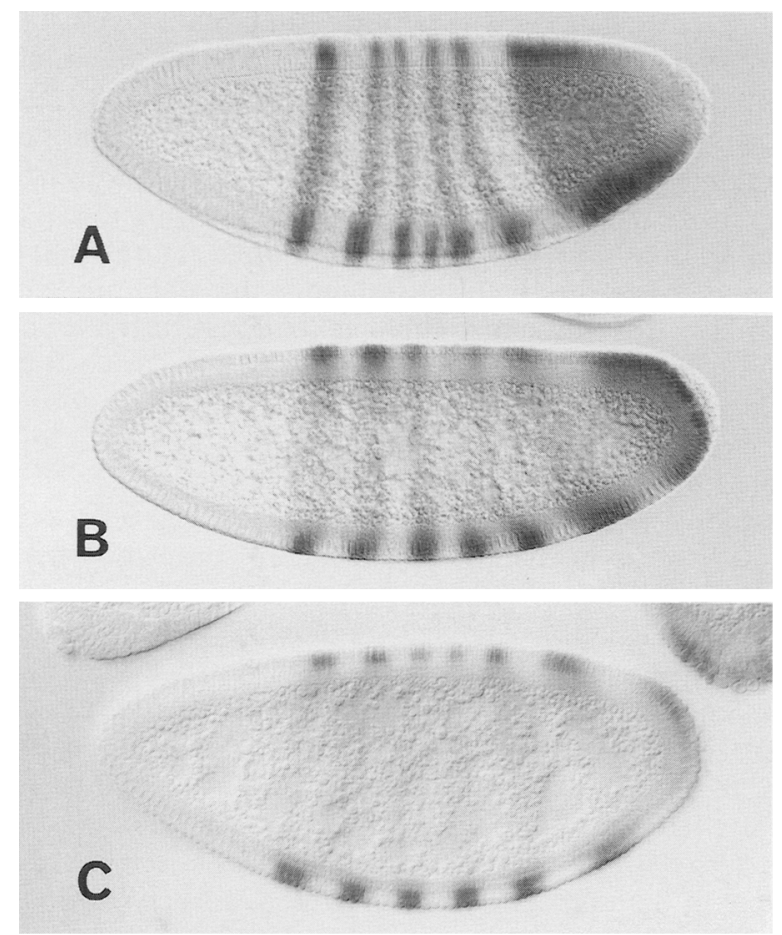

Figure 5. Progressive shifts in periodic $f t z$ expression caused by incremental change in the level of tor activity. $(A, B$, and $C)$ Patterns of periodic $f t z$ expression in embryos derived from $t r k$ tor ${ }^{R L 3} /$ trk females at 29,25 , and $22^{\circ} \mathrm{C}$ (all embryos are oriented with their anterior ends to the left, dorsal side up). At $29^{\circ} \mathrm{C}$, the activity of $t^{R}{ }^{R L 3}$ protein appears to be sufficiently high to allow the formation of all seven stripes, although the seventh stripe is unusually broad, extending toward the posterior pole. As both the temperature and level of $\operatorname{tor}^{R L 3}$ activity decrease $(B$ and $C)$, stripe 7 is shifted progressively toward the posterior pole; at $22^{\circ} \mathrm{C}$ it is sometimes eliminated entirely. Similarly, stripe 6 is also shifted posteriorly. In the complete absence of tor function (e.g., Fig. 3A), stripe 6 is now positioned at the posterior pole. Note also that at $29^{\circ} \mathrm{C}$, intermediate stripes, such as stripe $4(A)$ are sometimes partially or completely eliminated. We attribute this aspect of the phenotype to the increasing level of inappropriate $t o r^{R L 3}$ activity in the middle of the embryo that interferes with normal specification of the trunk segments.
(Klingler et al. 1988; Strecker et al. 1989; see also Fig. $3 \mathrm{D}, \mathrm{H}$ ), the tor $^{R L 3}$ mutation confers constitutive tor activity that is both temperature sensitive and independent of other terminal gene functions normally required for activating the wild-type protein (e.g., trk or tsl). Hence, in embryos derived from females that lack the trk gene function but carry a single copy of the tor ${ }^{R L 3}$ mutation, the level of tor activity depends simply on temperature. Therefore, we examined the development of the posterior terminalia in embryos derived from trk tor ${ }^{R L 3} /$ trk females at $17,22,25$, and $29^{\circ} \mathrm{C}$. At $17^{\circ} \mathrm{C}$ (when constitutive tor activity caused by the $\operatorname{tor}^{R L 3}$ mutation appears to be minimal), the development of embryos derived from trk tor ${ }^{R L 3} /$ trk females is similar although not identical to that of embryos derived from trk/trk females (i.e., both show loss of most or all of the terminal derivatives, although the loss of terminal structures is slightly less extreme in the progeny of trk tor ${ }^{R L 3} /$ trk females). At progressively higher temperatures, however, (when constitutive $t^{R L 3}$ activity increases), embryos derived from trk tor ${ }^{R L 3} /$ trk females differentiate progressively more terminal structures [unlike their trk/trk counterparts, which show only a slight amelioration of the extreme trk phenotype (Schüpbach and Wieschaus 1986a)]. Thus, as the temperature rises from $17^{\circ} \mathrm{C}$ to $29^{\circ} \mathrm{C}$, larvae derived from trk tor ${ }^{R L 3} /$ trk females recover first abdominal segments 7 , then 8 , and then more terminal derivatives such as complete posterior spiracles, the anal pads, anal sense organs, and anal tuft (Fig. 4). This phenotypic rescue can also be observed at the level of $f t z$ expression: As the temperature rises, the sixth stripe moves from the back end toward its normal position, the seventh stripe appears at the back end, and finally the seventh stripe shifts anteriorly toward its normal position (Fig. $5)$. At high temperature $\left(25-29^{\circ} \mathrm{C}\right)$ we also observe deletions of middle abdominal segments (and their corresponding $f t z$ stripes), presumably as a result of the rising level of inappropriate tor activity in the middle of the embryo.

Thus, under conditions in which the only tor activity results from temperature-sensitive constitutive activity of the $\operatorname{tor}^{R L 3}$ protein, we find a direct correlation between temperature, the types of terminal structures specified, and the number and position of terminal $\mathrm{ftz}$ stripes. This correlation argues that different levels of tor activity can specify distinct elements of the terminal pattern.

\section{Discussion}

Prior genetic experiments provide compelling evidence that the tor gene function is active only at the poles of the early embryo where it directs the formation of terminalia as opposed to more central portions of the body pattern (Klingler et al. 1988; Strecker et al. 1989; see Introductory section). Conversely, its absence or inactivity in the middle of the embryo is essential if this region is to form the middle body segments rather than contribute to the terminalia. The recent discovery (Sprenger et al. 1989) that tor is likely to encode a receptor tyro- 
sine kinase, suggests several possible mechanisms by which local tor activity is generated and the terminalia specified. The experiments described here argue strongly for particular mechanisms in each process.

\section{Local activation of tor}

Receptor tyrosine kinases contain an extracellular domain capable of binding particular ligands (e.g., EGF, PDGF) linked via a single transmembrane domain to an intracellular kinase domain (for review, see Yarden and Ullrich 1988; Williams 1989). In general, ligand binding induces activation of the kinase, which, in turn, triggers a variety of intracellular signaling pathways. As shown here, tor protein is expressed in tight association with the cell membrane of the early syncytial embryo, providing direct support for the proposal (Sprenger et al. 1989) that it functions as a surface receptor.

In principle localized tor activity may directly reflect a polarized distribution of the protein. However, we show that tor protein is ubiquitously expressed along the cell surface suggesting instead that its activity is locally triggered by contact with another factor present only at the poles. Other experiments support this conclusion and suggest that this ligand may be a localized component of the surrounding extracellular matrix secreted by the follicle cells.

First, we find that loss-of-function mutations in a number of other terminal genes block the activation of tor protein without altering its normal distribution. Hence, tor protein appears to be uniformly inert unless locally activated by a process that depends on these other gene functions. Of the four gene functions assayed, two, $t s l$ and $t r k$, appear to affect only the terminal signaling system, suggesting they play a specific role in this process.

Second, we show that the apparent distribution of active tor protein is not altered despite severalfold changes in the total concentration of tor protein. One simple interpretation of this result is that tor protein is normally present at levels that are saturating for a localized ligand necessary for its activation. Under these conditions, the distribution of active tor protein would directly reflect that of its putative ligand and remain unchanged if the concentration of tor protein were further increased.

Third, there is preliminary evidence that the $t s 1$ gene, which we show is required for tor activity, functions exclusively in follicle cells during oogenesis [H.G. Frohnhöfer and C. Nüsslein-Volhard, unpubl. (as cited in Sprenger et al. 1989)]. Hence, this gene may encode the putative tor ligand, or be involved in eliciting its local deposition. Our finding that tor protein is expressed during a restricted period just before and during the syncytial blastoderm stage suggests that interactions between tor and its putative ligand occur during this critical period, a conclusion that also agrees with the results of cytoplasmic rescue experiments (Klingler et al. 1988). Because proteins in the fluid layer between the early embryo and the surrounding vitelline membrane are free to diffuse (e.g., Warn and McGrath 1982), we suggest that the putative ligand remains spatially localized during oogenesis and early embryogenesis because it is tethered to the vitelline membrane, an extracellular matrix secreted by the follicle cells. It is notable that specialized subsets of polar cells are positioned at either end of the sheet of follicle cells surrounding the developing oocyte (Brower et al. 1982); these cells could be responsible for locally depositing the ligand as the vitelline membrane is secreted.

\section{Signal transduction by the tor protein}

The case of the tor ${ }^{R L 3}$ mutation presents a possible clue to the mechanism of signal transduction used by the tor protein. The tor ${ }^{R L 3}$ protein behaves as if it is capable of both ligand-dependent and ligand-independent activation (e.g., Fig. 3D,H), the latter conditional on temperature and concentration. We suggest that this unusual behavior reflects a deviation from the normal mechanism of signal transduction in which ligand binding activates the intracellular kinase domain by inducing oligomerization of the extracellular domains (e.g., Williams 1989). Accordingly, the tor $^{R L 3}$ mutation may allow the protein to oligomerize in a ligand-independent fashion. Under these circumstances, the concentration of monomers, as well as their rate of diffusion in the bilayer (a function of temperature), are likely to influence the amount of oligomerization and hence the level of constitutive tor activity. If the shift of the protein from the surface into intracellular vesicles is a consequence of the abnormal function of the tor ${ }^{R L 3}$ protein, then it could reflect high levels of ligand-independent oligomerization because it is known that receptor aggregation may trigger endocytosis (e.g., as in the case of the PDGF receptor; Yarden and Ullrich 1988; Williams 1989).

As suggested by Sprenger et al. (1989), activation of the tor protein is likely to lead to the phosphorylation of subordinate regulatory molecules, which, in turn, control the activation of zygotic segmentation genes that are responsible for generating terminal pattern. One intermediate in this putative signaling process appears to be lethal(1)pole hole [1(1)ph) (M. Klingler, unpubl. (as cited in Sprenger et al. 1989)l, which is likely to be the Drosophila homolog of the raf oncogene (Nishida et al. 1988). It is notable that the raf protein is itself a serine/ threonine kinase (Moelling et al. 1984). Hence, tor activity may trigger a cascade of spatially restricted kinase activities leading ultimately to the local activation of zygotic response genes, like the gap gene tailless $(t l l)$, which govern the development of the terminalia (Klingler et al. 1988; Strecker et al. 1989).

\section{Gradient morphogens in the terminal signaling system}

Localized tor activity is critical for specifying the portions of the body that generate terminal as opposed to central patterns. In this regard it is similar to both the $b c d$ and nos morphogen systems in which localized activity normally determines the portions of the body that develop anterior and posterior segment patterns. It has 
been shown recently, however, that these other morphogens play fundamentally different roles in their respective realms of action: The distribution of $b c d$ exerts an instructive influence on the organization of anterior body pattern (Frohnhöfer and Nüsslein-Volhard 1986, 1987; Driever and Nüsslein-Volhard 1988b; Driever et al. 1989; Struhl et al. 1989|, whereas localized nos activity simply defines a region in which posterior body pattern can be specified by other morphogens (Hülskamp et al. 1989; Struhl 1989; Irish et al. 1989). Hence, it is important to ask whether localized tor activity merely specifies the portions of the body that will develop as terminalia or actively dictates the organization of terminal patterns within these domains.

We addressed this question by setting up a situation in which the only tor activity present derives from the temperature-sensitive constitutive activity of the $\operatorname{tor}^{R L 3}$ protein. Using temperature to change the level of activity, we show that incremental increases in tor activity lead to the development of progressively more terminal structures at the posterior pole of the embryo (Fig. 4), as well as to corresponding shifts in the initial fate map (Fig. 5). These results provide evidence that the level of active tor protein can be causally related to the specification of particular portions of the terminal pattern and, hence, support the notion that the distribution of active protein plays an instructive rather than a permissive role in setting up the terminal pattern. It should be noted that all portions of the body do not invariably give rise to the same terminal structures in response to a given level of constitutive tor activity, presumably because of the activities of additional factors in more central portions of the body. However, higher levels of $t_{\text {tor }}^{R L 3}$ activity caused by increases in temperature or gene dosage are associated with the reduction or loss of middle trunk segments, and in the most extreme case with the formation of terminal structures in their place (the splice phenotype; Klingler et al. 1988; Strecker et al. 1989|. Hence, when the level of ectopic tor ${ }^{R L 3}$ activity is sufficiently high, these other factors appear to be suppressed or overridden thereby causing all parts of the body to differentiate similar terminal structures.

As discussed above, localized tor activity is likely to influence body patterning indirectly via its spatially restricted effects on the activation of one or more intracellular signaling molecules [e.g., l(1)ph and its substrates]. Since these locally activated signaling molecules could in principle diffuse within the cytoplasm, their distribution may not directly reflect that of active tor protein, but instead be more graded. Consequently, although it is possible that a gradient of active tor protein organizes terminal pattern, this need not be the case. Instead, a sharp step function of active tor protein at the surface could generate one or more gradients of phosphorylated intracellular substrates that specify the terminal pattern. Under these circumstances, different levels of constitutive $t^{R}{ }^{R L 3}$ activity would still reveal a causal relationship such as we observe, because they would trigger different levels of activity of these downstream factors. It is also notable that neither 1(1)ph nor tll mutations completely suppresses the development of terminalia, in contrast to tor mutations which do (Strecker et al. 1986; Klingler et al. 1988; Ambrosia et al. 1989). Hence, localized tor activity is likely to control the spatial activities of more than one intermediary signaling molecule and zygotic response gene, consistent with the notion that different levels of activity of tor or its target molecules dictate distinct molecular and morphological outcomes.

\section{Methods \\ Mutant genotypes}

The tor ${ }^{T C-17}$ mutation, a recessive loss-of-function allele of the torso gene induced by $\mathrm{P}-\mathrm{M}$ hybrid disgenesis, was kindly provided by Trudi Schüpbach. The $\operatorname{tor}^{R L 3}$ mutation was recovered as a female sterile mutation (Schüpbach and Wieschaus 1989) and subsequently shown to be an hypermorphic allele of the tor locus (Klinger et al. 1988). The tor ${ }^{D 4021}$ mutation is another gain-of-function allele of tor recovered as a dominant female sterile mutation (Klingler et al. 1988).

The mutations tor $^{P M}, t s^{035}$, and $t r k^{R A}$ are apparent null alleles of the tor, torsolike, and trunk loci. The $f_{S}(1) N^{121}$ and $f_{s}(1) p^{1906}$ mutations are recessive alleles of the female sterile (1) Nasrat and female sterile (1) pole hole loci that cause phenotypes similar to that of tor loss-of-function mutations. Both of these mutant alleles are exceptional-the remaining mutations in these two loci generally cause more severe pleiotropic phenotypes, frequently blocking normal development of the egg (Perrimon et al. 1986). The $b c d^{E 6}$ and osk ${ }^{166}$ mutations abolish activity of the bicoid and oskar genes and were used in cis to inactivate both the anterior and posterior determinant systems (Frohnhöfer and Nüsslein-Volhard 1986; Lehmann and Nüsslein-Volhard 1986; Nüsslein-Volhard et al. 1987; Struhl et al. 1989).

A chromosome carrying the $t r k^{R A}$ and $t o r^{R L 3}$ mutations in cis was obtained by recombination as follows: $t r k^{R A} \mathrm{pr} / \mathrm{cn}$ tor ${ }^{R L 3}$ females were outcrossed to males carrying the $C y O, p r \mathrm{cn}^{2} \mathrm{ba}$ lancer chromosome and putative $t r k^{R A}$ pr cn tor ${ }^{R L 3} / \mathrm{CyO}$, pr $\mathrm{cn}^{2}$ recombinant progeny selected on the basis of their purple cinnabar eye color. The presence of the tor ${ }^{R L 3}$ mutant allele was readily confirmed by the gain-of-function mutant phenotype; the presence of the $t r k^{R A}$ mutation was confirmed by progeny tests in which it was recombined away from the $\operatorname{tor}^{R L 3}$ mutation, again using the segregation of eye color phenotypes to identify potential recombinant progeny. Flies carrying the tor $^{R L 3}$ allele as well as the $t s 1^{035}, f_{S}(1) N^{121}$ and $f_{S}(1) p h^{1906}$ mutations were generated by standard genetic crosses, using the presence or absence of appropriate balancer chromosomes to distinguish homozygotes from heterozygotes.

\section{Cloning the tor gene}

An EMBL4 phage library of genomic DNA was derived from flies homozygous for the revertible P-element-induced mutation tor ${ }^{\text {TC-17 }}$ and screened with a P probe for homologous $\mathrm{P}$ sequences by standard means (Maniatis et al. 1982). Forty-five $P$ element-positive phage clones were selected. Duplicate nitrocellulose filters containing these clones displayed as a grid were then hybridized with total, ${ }^{32}$ P-labeled genomic DNA from wild-type embryos or embryos homozygous for a small deletion of the chromosome, $D f(2 R) S t 1$ (43B3-5; 43E18) (Ashburner et al. 1981) removing torso and neighboring loci (see Macdonald et al. 1986 for detailed protocol). Two clones appeared to hybridize 
only to wild-type DNA. Hybridization of one of these, $\lambda T 54$, in situ to the polytene chromosomes revealed that it mapped to the 43E region, which includes the torso locus. Appropriate probes from the $\lambda \mathrm{T} 54$ clone were used to obtain homologous DNAs from a wild-type (Oregon $\mathrm{R}$ ) library leading to the isolation of phage clones covering a contiguous region of approximately $30 \mathrm{~kb}$. Reverse Northern blotting experiments /Scott et al. 1983) were performed to identify sequences in this region that are transcribed during oogenesis and early embryogenesis. At the same time, Southern blotting experiments were performed on wild-type and tor ${ }^{T C-17}$ mutant DNAs to determine the location of the $\mathrm{P}$ element. These experiments showed that a $P$ element was inserted just upstream of the start site of a transcript present only in oocytes and early embryos. This putative tor transcript is located within an $11.5-\mathrm{kb} E c o \mathrm{RI}$ fragment that contains all the sequences necessary and sufficient for providing normal tor function as shown by the fact that it fully rescues the tor mutant phenotype when returned to the genome by P-element-mediated germ line transformation. The restriction map of this EcoRI fragment is essentially identical to that of an $E c o$ RI fragment containing the tor gene obtained independently by Sprenger et al. (1989).

\section{Generation of antiserum}

Several cDNA clones homologous to the tor transcript were obtained from an early embryo cDNA library kindly provided by Markus Noll. To raise an antibody against tor protein, different cDNAs were inserted into $\mathrm{pET}-3$ translation vectors (Rosenberg et al. 1987) in each of the three possible reading frames. After IPTG induction of the Escherichia coli LysS strain carrying the plasmid and electrophoresis of its protein on an SDS-polyacrylamide gel, one of these constructs gave rise to a distinct protein band. After partial purification this protein was used to raise rat polyclonal antibodies.

The rat serum was preabsorbed with late $(8-16 \mathrm{hr}$ old $)$ wildtype embryos and used to visualize putative tor protein by standard immunofluorescent and immunohistochemical techniques (see Macdonald and Struhl 1986). This antiserum fails to detect significant protein expression in embryos derived from homozygous tor ${ }^{T C-17}$ females confirming that it is indeed specific for the tor protein (see Fig. 1; we occasionally detect variable degrees of background staining in the yolk and pole cells of tor $^{T C-17}$ mutant embryos-such staining is spatially distinct from bona fide signal).

Because of the possibility of fixation artifacts and the vagaries of the immunohistochemical and immunofluorescent staining methods employed, all analyses of tor protein expression in mutant genotypes were performed in strict parallel with wildtype controls as follows. Embryos of a given genotype were first mixed with roughly equal numbers of $b c d$ osk mutant embryos of the same age and then dechorionated, fixed, and stained together. bcd osk embryos do not form pole cells, allowing them to be readily distinguished from embryos of the other genotype. As we are unable to detect any significant differences in tor protein expression in wild-type and bcd osk mutant embryos, we treat these embryos as wild-type controls.

\section{Confocal scanning microscopy}

Embryos were fixed and incubated with the primary rat antiserum to tor protein as usual and then washed to remove any unbound antibodies. They were subsequently incubated with a preabsorbed goat anti-rat immunoglobulin coupled to fluorescein isothiocyanate (FITC), washed, mounted in $50 \%$ glycerol with $2.5 \mathrm{mg} / \mathrm{ml} p$-phenylenediamine added as an antibleaching agent and analyzed under the argon ion laser beam of an MRC-500 confocal imaging system (Bio-Rad Microscience). Embryos from females with two or eight copies of the torso gene were examined. As in immunohistochemical preparations, we found the patterns of expression to be indistinguishable, although the level of expression was much higher in the case of eight-copy embryos.

\section{Generation of flies with extra copies of the tor gene}

An EcoRI fragment of about $11.5 \mathrm{~kb}$ was introduced into the germ-line by P-element-mediated transformation using the $P\left(r y^{+}\right)$vector Carnegie 20 (Rubin and Spradling 1983). Females homozygous for the $\operatorname{tor}^{P M}$ mutation, but carrying a single copy of this transduced gene give rise to phenotypically wild-type progeny confirming that the $11.5-\mathrm{kb}$ EcoRI fragment contains in the intact $t^{+}{ }^{+}$gene.

Several independent transformant lines were recovered with $P\left(\mathrm{ry}^{+}, \mathrm{tor}^{+}\right)$insertions on the second or third chromosomes and shown to fully rescue the tor mutant phenotype in single copies. Two such insertions on the third chromosome were placed in cis by standard genetic techniques involving recombination and progeny testing. Flies homozygous for this third chromosome as well as for a second chromosome with another insertion carry a total of eight copies of the tor $^{+}$gene.

A bcd $d^{-}$osk $^{-}$chromosome carrying a single $P\left(r y^{+}\right.$, tor $\left.^{+}\right)$insertion in cis was generated by standard genetic techniques taking advantage of the tight linkage of the bcd osk and ry loci. The presence of the insertion was confirmed by the ability of the chromosome to rescue the phenotype of the torso- mutations. Flies homozygous for this third chromosome as well as a second chromosome carrying another $P\left(r y^{+}\right.$, tor $\left.^{+}\right)$insertion carry six copies of the tor gene in a $b c d^{-}$osk $^{-}$background.

\section{Acknowledgments}

We thank Trudi Schüpbach for making the $\operatorname{tor}^{T C-17}$ mutation available to us for cloning the tor locus. We also thank Trudi Schüpbach, Michael Ashburner, Christianne Nüsslein-Volhard, Norbert Perrimon, and Janos Szabad for providing the various mutant alleles used in this study; Steve Mount for the P-probe; and Henry Krause and Paul Macdonald for the $f t z$ and $K r$ antisera. We gratefully acknowledge excellent technical assistance provided by Pat Fazio Miceli, Caroline Kopec, and Jane AlbertHubbard; help with the confocal scanning microscope by Dan Felsenfeld and Ira Schierer; and criticisms and suggestions on the manuscript by Richard Axel, Janice Fischer, Ken Howard, Tom Jessell, Peter Lawrence, and Robin Wharton. This work was supported by the Howard Hughes Medical Institute, the McKnight Foundation for Neuroscience, the Sloan Foundation, and a long-term EMBO fellowship to J.C. J.C. is on leave from the C.S.I.C., Spain.

\section{Note added in proof}

We determined recently that the lesion responsible for the tor ${ }^{R L 3}$ gain-of-function phenotype maps to the extracellular domain of the protein. This is consistent with our proposal that the mutation causes a change in this portion of the molecule, which allows oligomerization in the absence of ligand. However, we only observe the apparent shift of protein from the cell surface to abnormal intracellular vesicles (Fig. 1F, G) in embryos derived from females homozygous for the original tor ${ }^{R L 3}$ bearing chromosome and not in embryos derived from females in which the second copy of the mutant gene is inserted on a $\mathrm{P}$ 
element at a different location. Hence, the abnormal partitioning of $t o r^{R L 3}$ protein shown in Figure 1 does not appear to be attributable to the lesion conferring ectopic gain-of-function, but rather to a second site mutation in another gene.

\section{References}

Ambrosio, L., A.P. Mahowald, and N. Perrimon. 1989. 111)pole hole is required maternally for pattern formation in the terminal regions of the embryo. Development 106: 145-148.

Ashburner, M., P. Angel, C. Detwiler, J. Faithfull, D. Gubb, G. Harrington, T. Littlewood, S. Tsubota, V. Velissariou, and V. Walker. 1981. New Mutants Drosophila Inform. Serv. 56: $186-191$.

Berleth, T., M. Burri, G. Thoma, D. Bopp, S. Richstein, G. Frigerio, M. Noll, and C. Nüsslein-Volhard. 1988. The role of localization of bicoid RNA in organizing the anterior pattern of the Drosophila embryo. EMBO J. 7: 1749-1756.

Brower, D.L., R.J. Smith, and M. Wilcox. 1981. Differentiation within the gonads of Drosophila revealed by immunofluorescence. J. Embryol. Exp. Morphol. 63: 233-242.

Counce, S.J. and D.A. Ede. 1957. The effect on embryogenesis of a sex-linked female-sterile factor in Drosophila melanogaster. J. Embryol. Exp. Morphol. 5: 404-421.

Degelmann, A., P.A. Hardy, N. Perrimon, and A.P. Mahowald. 1986. Developmental analysis of the torso-like phenotype in Drosophila produced by a maternal-effect locus. Dev. Biol. 115: 479-489.

Driever, W. and C. Nüsslein-Volhard. 1988a. A gradient of bicoid protein in Drosophila embryos. Cell 54: 83-93.

. 1988b. The bicoid protein determines position in the Drosophila embryo in a concentration-dependent manner. Cell 54: 95-104.

Driever, W., G. Thoma, and C. Nusslein-Volhard. 1989. The bicoid protein is a positive regulator of hunchback transcription in the early Drosophila embryo. Nature 340: 363367.

Foe, V.E. and B.M. Alberts. 1983. Studies of nuclear and cytoplasmic behavior during the five mitotic cycles that precede gastrulation in Drosophila embryogenesis. J. Cell Biol. 61: $31-70$.

Frohnhöfer, H.G. and C. Nüsslein-Volhard. 1986. Organization of anterior pattern in the Drosophila embryo by the maternal gene bicoid. Nature 324: 120-123.

-1987. Maternal genes required for the anterior localization of bicoid activity pattern in the embryo of Drosophila. Genes Dev. 1: 880-890.

Gaul, U. and H. Jäckle. 1987. Pole region-dependent repression of the Drosophila gap gene Krüppel by maternal gene products. Cell 51: 549-555.

Hülskamp, M., C. Schröder, C. Pfeifle, H. Jäckle, and D. Tautz. 1989. Posterior segmentation of the Drosophila embryo in the absence of a maternal posterior organizer gene. Nature 338: $629-632$.

Ingham, P.W. 1988. The molecular genetics of embryonic pattern formation in Drosophila. Nature 335: 25-34.

Irish, V., R. Lehmann, and M. Akam. 1989. The Drosophila posterior-group gene nanos functions by repressing hunchback activity. Nature 338: 646-648.

Klingler, M., M. Erdelyi, J. Szabad, and C. Nüsslein-Volhard. 1988. Function of torso in determining the terminal anlagen of the Drosophila embryo. Nature 335: 275-277.

Lehmann, R. 1988. Phenotypic comparison between maternal and zygotic genes controlling the segmental pattern of the Drosophila embryo. Development (suppl.) 104: 17-27.

Lehmann, R. and C. Nüsslein-Volhard. 1986. Abdominal seg- mentation, pole cell formation and embryonic polarity require the localized activity of oskar, a maternal gene in Drosophila. Cell 47: 141-152.

1987. Involvement of the pumilio gene in the transport of an abdominal signal in the Drosophila embryo. Nature 329: $167-170$.

Lewis, E.B. 1978. A gene complex controlling segmentation in Drosophila. Nature 276: 565-570.

Macdonald, P.M. and G. Struhl. 1986. A molecular gradient in early Drosophila embryos and its role in specifying the body pattern. Nature 324: 537-545.

Macdonald, P.M., P. Ingham, and G. Struhl. 1986. Isolation, structure and expression of even-skipped: A second pair-rule gene containing a homeobox. Cell 47: 721-734.

Maniatis, T., E.F. Fritsch, and J. Sambrook. 1982. Molecular cloning: A laboratory manual. Cold Spring Harbor Laboratory, Cold Spring Harbor, New York.

Mlodzik, M., C.M. De Montrion, Y. Hiromi, H.M. Krause, and W.J. Gehring. 1987. The influence on the blastoderm fate map of maternal-effect genes that affect the antero-posterior pattern in Drosophila. Genes Dev. 1: 603-614.

Moelling, K., B. Heimann, P. Beimling, U.R. Rapp, and T. Sander. 1984. Serine- and threonine-specific protein kinase activities of purified gag-mil and gag-raf proteins. Nature 312: $558-561$.

Nishida, Y., M. Hata, T. Ayaki, H. Ryo, M. Yamagata, K. Shimizu, and Y. Nishizuka. 1988. Proliferation of both somatic and germ cells is affected in the Drosophila mutants of raf proto-oncogene. EMBO I. 7: 775-781.

Nüsslein-Volhard, C. and E. Wieschaus. 1980. Mutations affecting segment number and polarity in Drosophila. Nature 287: 795-801.

Nüsslein-Volhard, C., H.G. Frohnhöfer, and R. Lehmann. 1987. Determination of anteroposterior polarity in Drosophila. Science 238: 1675-1681.

Perrimon, N., L. Engstrom, and A.P. Mahowald. 1985. A pupal lethal mutation with a paternally influenced maternal effect on embryonic development in Drosophila melanogaster. Dev. Biol. 110: 480-491.

Perrimon, N., D. Mohler, L. Engstrom, and A.P. Mahowald. 1986. X-linked female-sterile loci in Drosophila melanogaster. Genetics 113: 695-712.

Rosenberg, A.H., B.N. Lade, D. Chui, S. Lin, J.J. Dunn, and F.W. Studier. 1987. Vectors for selective expression of cloned DNAs by T7 RNA polymerase. Gene 56: 125-135.

Rubin, G.M. and A.C. Spradling. 1983. Vectors for P elementmediated gene transfer in Drosophila. Nucleic Acids Res. 11: 6341-6351.

Schüpbach, T. and E. Wieschaus. 1986. Maternal-effect mutations altering the anterior-posterior pattern of the Drosophila embryo. Wilhelm Roux's Arch. Dev. Biol. 195: 302317.

- 1989. Female sterile mutations on the second chromosome of Drosophila melanogaster. Maternal effect mutations. Genetics 121: 101-117.

Scott, M.P., A.M. Wiener, T.I. Hazelrigg, B.A. Polisky, V. Pirrotta, F. Scalenghe, and T.C. Kaufman. 1983. The molecular organization of the Antennapedia locus of Drosophila. Cell 35: 763-776.

Sprenger, F., L.M. Stevens, and C. Nüsslein-Volhard. 1989. The Drosophila gene torso encodes a putative receptor tyrosine kinase. Nature 338: 478-483.

Strecker, T.R., K. Kongsuwan, J.A. Gengyel, and J.R. Merriam. 1986. The zygotic mutant tailless affects the anterior and posterior ectodermal regions of the Drosophila embryo. Dev. Biol. 113: 64-76. 


\section{Casanova and Struhl}

Strecker, T.R., S.R. Halsell, W.W. Fisher, and D.D. Lipshitz. 1989. Reciprocal effects of hyper- and hypoactivity mutations in the Drosophila pattern gene torso. Science 243: $1062-1066$.

Struhl, G. 1989. Differing strategies for organizing anterior and posterior body pattern in Drosophila embryos. Nature 338: 741-744.

Struhl, G., K. Struhl, and P.M. Macdonald. 1989. The gradient morphogen bicoid is a concentration-dependent transcriptional activator. Cell 57: 1259-1273.

Turner, F.R. and A.P. Mahowald. 1976. Scanning electron microscopy of Drosophila embryogenesis. Dev. Biol. 50: 95108.

Warn, R.H. and R. Magrath. 1982. Observations by a novel method of surface changes during the syncytial blastoderm stage of the Drosophila embryo. Dev. Biol. 89: 540-548.

Williams, L.T. 1989. Signal transduction by the platelet-derived growth factor receptor. Science 243: 1564-1570.

Yarden, Y. and A. Ullich. 1988. Growth factor receptor tyrosine kinases. Annu. Rev. Biochem. 57: 443-478. 


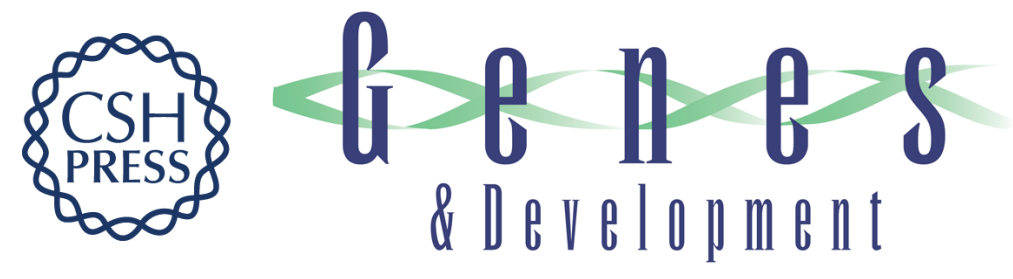

\section{Localized surface activity of torso, a receptor tyrosine kinase, specifies terminal body pattern in Drosophila.}

J Casanova and G Struhl

Genes Dev. 1989, 3:

Access the most recent version at doi:10.1101/gad.3.12b.2025

References This article cites 44 articles, 9 of which can be accessed free at:

http://genesdev.cshlp.org/content/3/12b/2025.full.html\#ref-list-1

License

Email Alerting

Service

Receive free email alerts when new articles cite this article - sign up in the box at the top right corner of the article or click here.

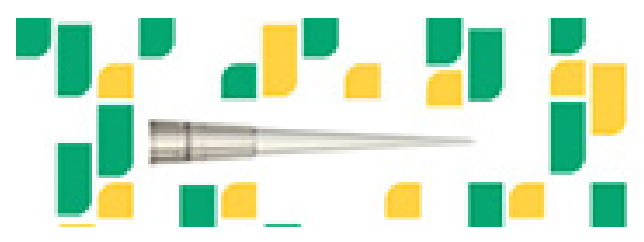

Focused on your science.

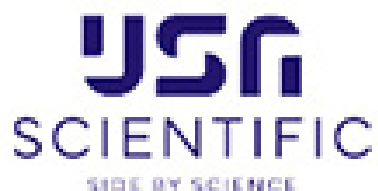

Copyright @ Cold Spring Harbor Laboratory Press 